\title{
The social construction of educational technology through the use of authentic software tools
}

\author{
Allan Jones* and Christopher Bissell \\ Communication and Systems, Faculty of Mathematics, Computing and Technology, Open \\ University, Milton Keynes, UK
}

(Received 26 November 2010; final version received 14 September 2011)

\begin{abstract}
A major strand of science and technology studies in recent decades has related to the social construction of technology (SCOT) movement, whose adherents maintain that technological systems are determined just as much by social forces as by technological ones. Taking this SCOT notion as a starting point, and putting a focus on the user, this paper looks at some examples of the educational use of software tools that exploit the functionality of the software in ways far removed from the original design. Examples include the use of spreadsheets, graphics editors and audio editors, and online translation software. Connections are made between the social construction of technology and constructivist pedagogy, particularly in relation to authentic learning.
\end{abstract}

Keywords: social construction of technology; learner empowerment; spreadsheets; educational technology; proprietary software

\section{Introduction: the sociology of technology}

Over the last 30 years or so there has been much debate amongst historians and sociologists concerning the interplay of technology and society in the development and functioning of socio-technological systems. One outcome of this work has been a general move away from a traditional, technologically determinist, stance. Most historians and sociologists - and many technologists - would now take the view that technology has a socially constructed aspect, although ideas about the mechanism of this construction vary. (See Berg and Selinger 2007 for a survey of the views of some prominent thinkers; also Mackenzie and Wajcman 1999 for essays by eminent scholars regarding social construction of technology.) In this paper we present some examples of the use of technology in an educational context, but we take as our primary analytic frame ideas from recent work in the sociology of technology.

As part of their characterisation of technological determinism, Smith and Marx (1994, x) cite the prevalence of popular narratives in which a technological innovation appears suddenly and "causes important things to happen". For example Gutenberg's development of the printing press using moveable type "is depicted as a virtual cause of the Reformation" in Europe (Smith and Marx 1994, x). Such popular fables concentrate on apparent consequences of inventions rather than their

*Corresponding author. Email: a.jones@open.ac.uk 
genesis, and 'give credence to the idea of 'technology' as an independent entity, a virtually autonomous agent of change" (Smith and Marx 1994, xi). Other factors such as socio-economics, politics, culture and ideological formations are often obscured or ignored. Technological determinism has largely been sidelined in scholarly histories of technology (although Schroeder 2007 mounts a nuanced defence); however, it is still often found in the media, politics and business. It betrays itself in references to, for example, technological innovations that will create new social forms or practices, or disrupt existing business practices. In such accounts, the social aspect of technology resides in the way technology affects society. The technology is taken for granted, and society carries its imprint. An analogy might be drawn with the weather, which unfolds independently of human agency, but affects human activity. To ask, therefore, what the effect of a particular technology on education might be is implicitly to adopt a determinist stance.

\section{Social construction of technology}

The scholarly turn away from technological determinism and towards various forms of 'social shaping of technology' had its origins in a number of centres in Britain and elsewhere from the 1970s onwards. An excellent review of the development of this movement can be found in the survey article by Williams and Edge (1996), which includes an extensive bibliography. One particular strand of social shaping sails under the social construction of technology (SCOT) flag, and SCOT ideas inform this paper. SCOT as a movement developed from a seminal conference at Twente University of Technology in the Netherlands in 1984 (Bijker, Hughes, and Pinch, 1987; see also Bijker and Law 1992; Bijker 1995; Pinch and Bijker 1986; MacKenzie and Wajcman 1999). Distinctive features of the SCOT framework include the notion of 'relevant social groups'. Such groups are defined as "those groups who share a meaning in an artifact" and can include designers or users (Kline and Pinch 1996, 765). This identification of users as a relevant social group is especially germane to this paper; indeed the title of Kline and Pinch's (1996) paper, 'Users as Agents of Technological Change', neatly summarises the focus of the present article on users rather than on designers of technology. Another concept emphasised by SCOT is interpretative flexibility, in which "different social groups associate different meanings with artifacts" (Kline and Pinch 1996, 766). In essence, what a technology means, or is for, cannot be stated definitively because "the same artifact can mean different things to different social groups of users" (Kline and Pinch 1996, 766).

The historian David Edgerton made a significant contribution more recently in his examination of what precisely is meant by 'technological determinism' and his conclusion that the concentration on innovation in 'progressivist' accounts of technology has led to a grave omission of studies of the use and users of technology. His thought-provoking paper directed at historians of technology (Edgerton 1998, 1999) was followed by a well-received book for a popular audience (Edgerton 2006). Edgerton gives examples of how studying technology use changes our assessment of technological significance. For example, Edgerton finds ample evidence of 'old' technology (such as steam and coal power) continuing in widespread use - and continuing to be economically and socially dominant - long after the introduction of newer technologies that are claimed to have superseded earlier ones (Edgerton 2006, xiv-xviii). 
In this context, 'innovation' and 'use' signify much more than different phases in the life of the technology - much more than whether a technology is new or mature. Rather, they connote a shift of analytical interest from creation to usage, and a shifting of who defines what the technology is, or what its purpose is. With innovation, interest typically centres on novelty, on difference from competitors, and (often) on potential wealth generation. With 'technology-in-use', on the other hand, interest centres on how the technology is employed 'in the wild', often by people for whom innovation is of less significance than, for example, cheapness, ease of use and repair, and durability. What is more, 'technology in use' tends to have a more overt socially constructed aspect, in the sense that an established technology is often adapted by users to meet local needs. For example, in parts of Africa, mobile phones have been developed into systems for remitting money between dispersed family members (Batchelor 2005).

\section{SCOT and education}

Educational technology has tended to suffer from an emphasis on, and possibly excessive claims for, technological innovation and novelty. For example, film, radio and television had their early proponents, but in the classroom failed to deliver what was predicted (Cuban 1986). Digital technology has similarly been presented as educationally transformative, a recent high-profile example being the One Laptop per Child project:

As the pace of change in the world increases dramatically, the urgency to prepare all children to be full citizens of the emerging world also increases dramatically. No one can predict the world our children will inherit. The best preparation for children is to develop the passion for learning and the ability to learn how to learn.

The root cause of the rapid change, digital technology, also provides a solution. When every child has a connected laptop, they have in their hands the key to full development and participation. (Anon, n.d.)

The actual, practical deployment and use of educational technology has received plenty of scholarly study. For example, Pettit and Kukulska-Hulme (2007) survey some educational uses of mobile devices; Smith et al. (2005) give a review of the literature on the use of interactive whiteboards in the (predominantly British, school) classroom; Creanor et al. (2008) report the findings of the Learner Experience of e-Learning project in UK post-16 education; Kear $(2004,2011)$ has examined the educational use of asynchronous networked environments (Kear 2004), and online social networks (Kear 2011). We would claim, however, that the socially constructed aspect of 'use' in educational technology has been little explored.

What benefit might come from exploring 'use' in this sense? One possibility is an enlargement of our conception of what counts as an educational resource. Indeed, through interpretative flexibility, what makes a piece of technology educational is not necessarily inherent in the design of the technology; it might instead be a question of usage. Later in this paper we give four brief case studies of software tools being used educationally. In all cases these tools were not designed for educational use, and in all cases their principal application is so well established as perhaps to lead to their educational potential being overlooked. 
Another possible benefit of the SCOT perspective is to suggest ways of supporting the kind learning that educators wish students to experience. In the case studies that follow, software tools are used in ways that foster students' understanding through "an active process of creating hypotheses and building new forms of understanding though activity" (Mayes and de Freitas 2007, 17). That is to say, constructivist learning.

Finally, there is the question of authenticity. 'Authenticity' in relation to learning has been explored by Brown, Collins, and Duguid (1989) in their classic paper 'Situated Cognition and the Culture of Learning'. They argue that "knowledge is situated, being in part a product of the activity, context and culture in which it is developed and used" (Brown, Collins, and Duguid 1989, 32). They liken conceptual knowledge to a set of tools. Mere ownership of tools is no guarantee of competence in their use. Only through mastery of tool use in authentic contexts does one come to a proper understanding of what the tool is for and how it is used. Brown, Collins, and Duguid $(1989,33)$ note that: "[I]t is common for students to acquire algorithms, routines and decontextualised definitions that they cannot use". Students' inability to use these acquired practices arises from the artificiality of the academic culture in which they encounter them. Students ought instead to learn through 'authentic activity' - an educational process described as cognitive apprenticeship. The SCOT perspective can help here, as the case studies show.

In the four case studies that follow, the software tools might not seem novel or exciting, but that, in a sense, is the point. None of these tools is 'the latest thing', and no one is likely to claim that they will revolutionise education. They are all fairly mature tools, and used daily by countless practitioners with little thought other than the need to get a job done, just as a joiner might use a hammer and nails.

\section{Spreadsheets}

Originally designed for financial planning and analysis, early spreadsheets were soon extended by the inclusion of a full range of mathematical functions and even a high-level programming language such as Visual Basic. The late 1980s and 1990s saw a rash of papers in the science and engineering education literature on using spreadsheets as a teaching tool (for example, Benson and Kopp 1991; Healy and Sutherland 1992; Kral 1991; Stanton, Drozdowski, and Duncan 1993). The vast majority of the scientific and engineering educational applications reported in the literature used spreadsheets simply to set up and solve standard mathematical models as part of simulations of processes or systems. Many examples used in practice, including some developed by the UK Open University, deliberately excluded the user from exploring the model behind the simulation by hiding cell contents or making them read-only. Comparatively few initiatives took the line of asking students to construct the spreadsheets themselves by building the modelling assumptions directly into the spreadsheet formulae. The following two examples are illustrative of the latter approach, in which students - either individually or working as a group - build the simulations from scratch.

The first example is an illustration of how a digital signal can be regenerated either without error or with a small number of errors when the signal is corrupted by noise. The technical spreadsheet knowledge required is fairly elementary, essentially being the ability to use the spreadsheet's random number and integer rounding functions and to plot bar and line charts. Figure 1 shows the spreadsheet. 
Column A holds a random sequence of \pm 1 , representing a series of digital bits of data. (Usually bits are represented as one or zero, but in some cases, as here, +1 and -1 are used.) The top graph, labelled 'original data', shows the data. Column B represents these data as received. It is corrupted by noise, simulated here by adding random amounts to each original bit of data. The second graph, 'received waveform', is the corrupted signal. A simple rule for regenerating the original data is to say that wherever the received waveform is negative, the original signal was -1 ; and wherever the received waveform is positive the original signal was +1 . The data regenerated by this rule are shown in the third graph of Figure 1. However, the random nature of the corruption means the rule sometimes leads to error, shown by the fourth graph of Figure 1, which is produced by comparing the third and first graphs. Students can experiment by varying the amount of added noise and viewing the corresponding error(s).

The second example shows a spreadsheet equivalent of a physical model used to demonstrate the binomial function. In the physical model, on the right of Figure 2, ball bearings fall through a set of pins, hitting several pins in sequence (as in a pinball game), and coming to rest in partitioned compartments at the bottom. At each encounter with a pin, a ball bearing is deflected either to the right or the left unpredictably. The heights of the columns of balls at the bottom come to

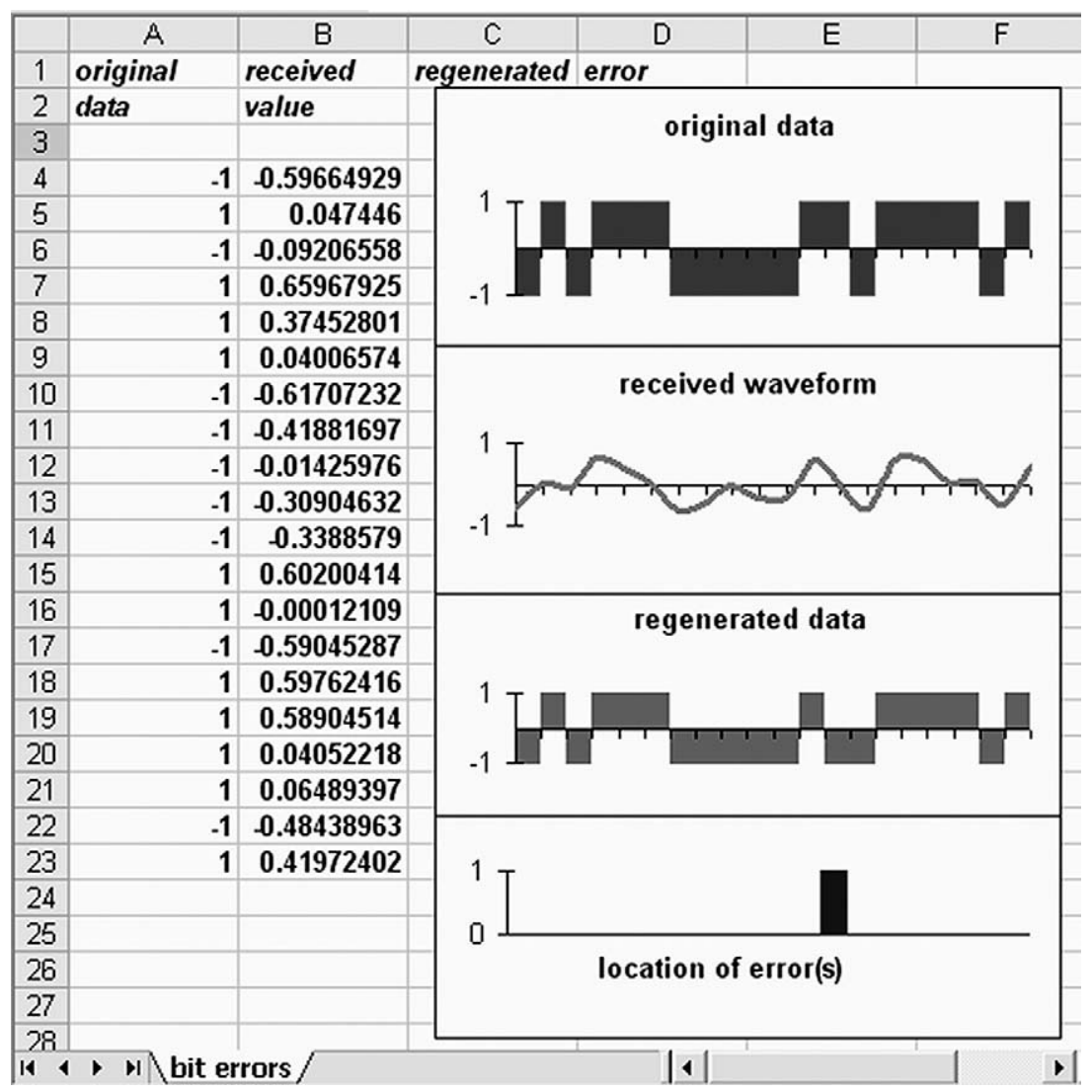

Figure 1. How a digital signal can be regenerated with or without errors. 

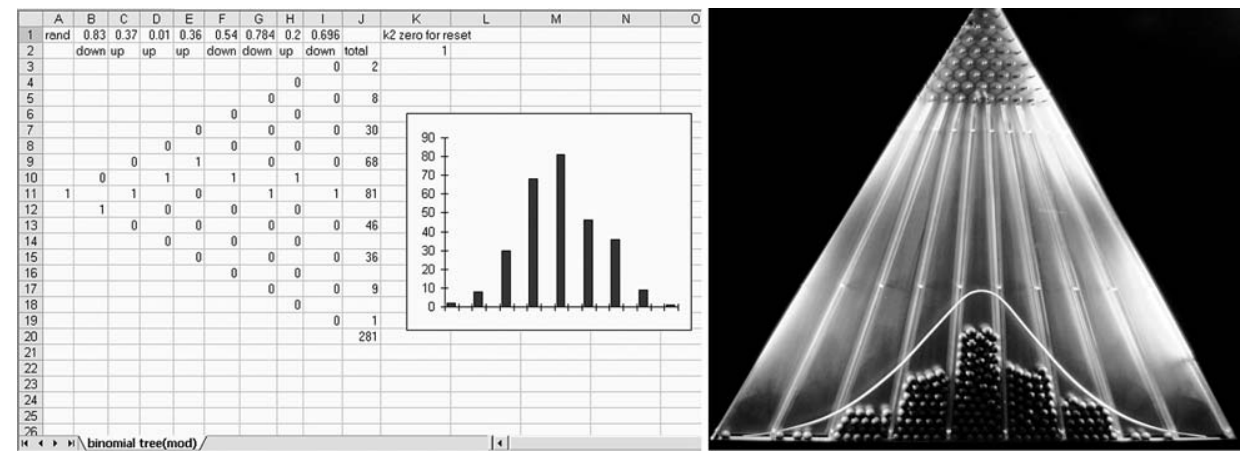

Figure 2. Spreadsheet (left) and physical model (right) of binomial function.

Source: Physical model courtesy of Antoine Taveneaux (used under Creative Commons).

resemble the classic binomial distribution, an approximation to the Gaussian or 'normal' bell-curve, with most in the centre and fewest to the left and right. (To arrive at the extreme left or right, a ball must undergo deflections that are all in the same direction, or nearly so. This is less likely than the ball undergoing a mixture of deflections, and so happens less often.)

In the spreadsheet model (Figure 2), ones trickle in from the left, and pass from left to right through each column. In moving from one column to the next, the one is randomly 'deflected' diagonally upwards or downwards. Finally the ones are summed in the 'total' column and plotted as a chart.

There are three points we wish to emphasise here (and which apply to the remainder of the examples presented in this paper). The first is that the students construct the spreadsheet models for themselves. Students determine the calculations that must be made and the internal spreadsheet functions that must be used, and students construct the spreadsheet to carry out the simulations. Secondly, in constructing the models, students become more competent users of the software, as well as improving their understanding of (in this case) digital signal transmission and the binomial distribution. So far, then, these spreadsheets provide examples of a constructivist learning approach (Abbey 2000; Lave 1998).

Our third point, however, relates these examples to the social construction of technology mentioned at the start of this article. In their use of the spreadsheet software, the teacher and students have turned the package into something quite different from what was originally envisaged by the developers, and also into something very different from a simple mechanical solution of an underlying mathematical model. That is to say, the technology is socially constructed through the adaptation of an existing, generic platform to an educational purpose.

There is nothing particularly innovative in the final results of these activities. Similar simulations abound on the Web or in classrooms. The key difference in this approach is that not only is there pedagogical constructivism in the student activity, but there is also the social construction of a new educational technology.

In this example the learner's creation of an approximate model has an authentic quality. The learner creates a model in the way an engineer would- through deliberation over assumptions, assessment of interacting factors, and so on. The learner's model is then realised in the spreadsheet. This type of modelling is standard practice in engineering, where high precision is not always required or desirable. Rather, 
what engineers often require is a quick test of the soundness of their interpretation of a problem, for which a quick, simple model might be adequate.

\section{Graphics editor}

Our second example concerns the use of graphics processing software. Irfanview is a freeware graphics editing and manipulation package, offering functions very similar to those of numerous other graphics editors. In a UK Open University Level 1 module, however, rather than simply using the package to edit images, students use it to explore the digital representation of images and the fundamentals of image compression.

One particularly useful feature is the 'image properties' window (Figure 3), included in the package to enable the user to quickly observe the characteristics of the image in terms of the resolution, the file size, the colour palette involved, and

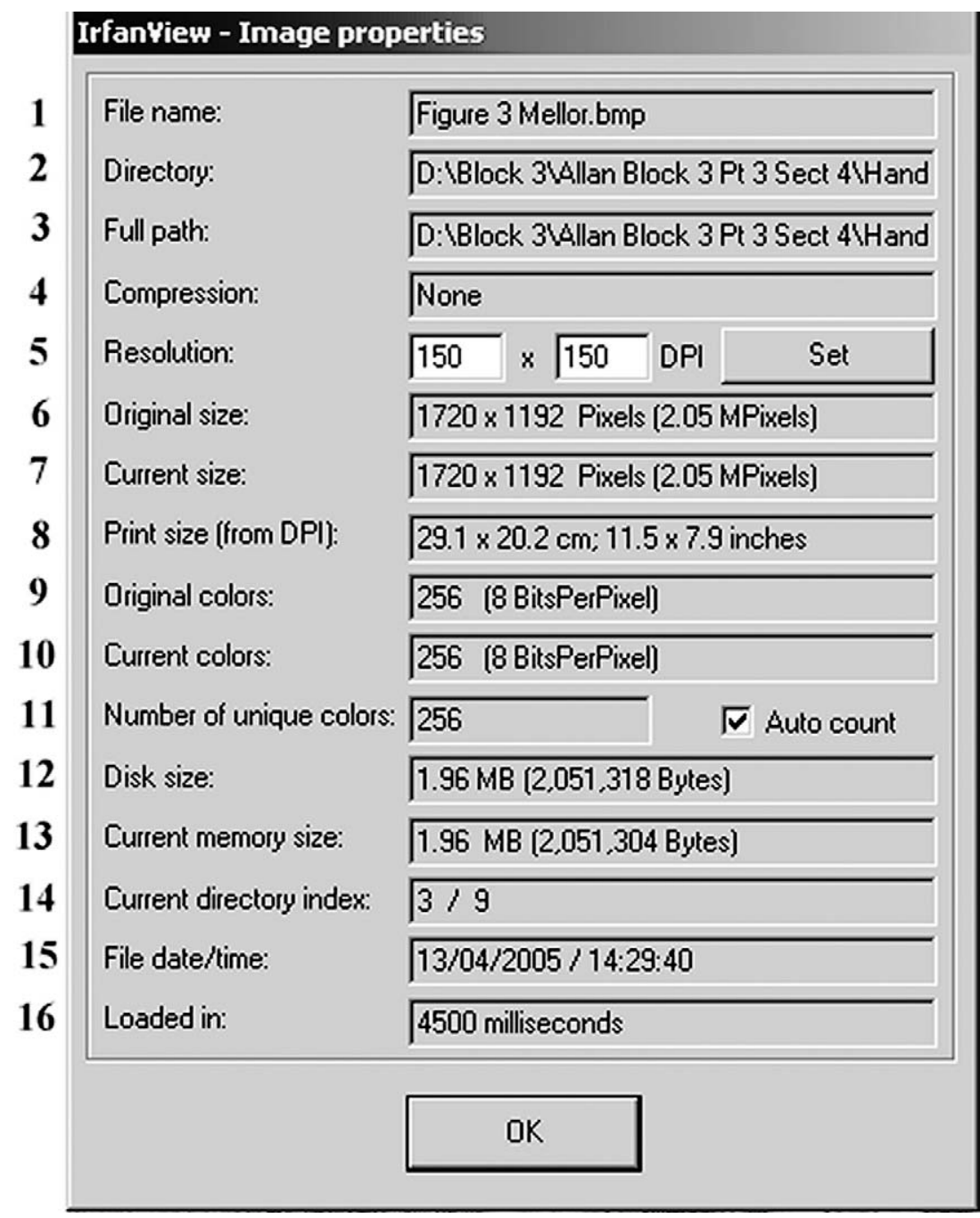

Figure 3. Image properties window of Irfanview. 
so on. Students explore the suitability of various compression algorithms for particular types of image. In Figure 3, line 6 gives the number of pixels, line 12 the compressed size (if the file format is one that uses compression) and line 13 the uncompressed size. Line 10 shows the number of colours used. With the aid of this information the student can explore the result of compressing various types of image - full colour, charcoal sketch, pen-and-ink drawing - and come to sensible conclusions about the appropriateness or otherwise of particular techniques in relation to the nature of the image. For example, there is little point in using 256 colours (eight bits per pixel) for a pen-and-ink drawing where each pixel is either black or white, and can be represented by a single bit.

\section{Audio editor}

Adobe Audition is a (moderately expensive) professional audio editor that is well established in areas such as local radio. In a Level 2 module at the UK Open University, students use it to generate audio waveforms, manipulate them, and relate the results to their theoretical understanding of the principles taught in the module. As was the case with Irfanview, however, the module exploits various facilities of the software for a practical exploration of some theoretical topics - in this case, the study of elements of acoustics and psychoacoustics. Figure 4 shows just one example from the student activities, in which the difference between a chord tuned to pure ratios and the same chord using equal temperament is illustrated audibly and visually. ${ }^{1}$ The waveform of the equally tempered chord shows the characteristic pulsation of amplitude, or 'beating', associated with the use of 'impure' frequency ratios in equal temperament. ${ }^{2}$

In this activity, students create the two sorts of chord for themselves, and see and hear the results. Students can easily manipulate any of the notes in the chords as they please, and experience the consequences. In the past the UK Open University might well have produced its own in-house computer-aided learning material to teach such matters, or maybe a recorded audio-visual demonstration by an expert.

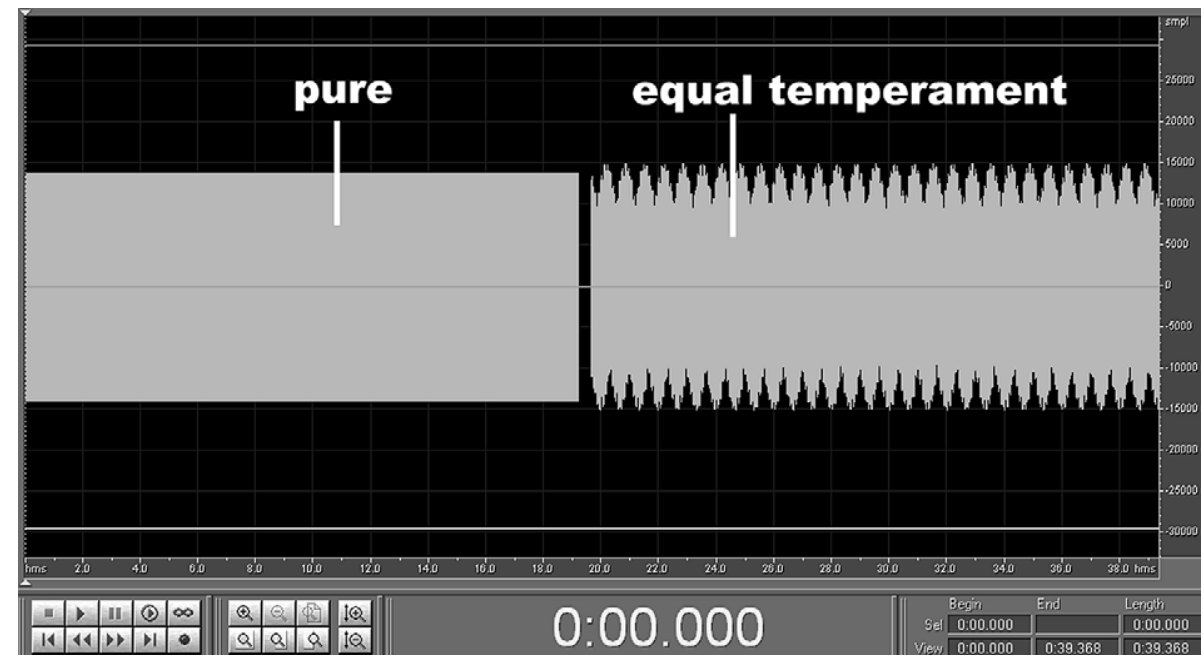

Figure 4. Different wave 'envelopes' for a chord with pure tuning and equal temperament. 


\section{Online translation: a personal anecdote}

Our final example is admittedly a little idiosyncratic, yet further reinforces the general argument of this paper. It is an example of the use of the Web as an interactive resource that goes beyond the simple search for information, as well as another example of user re-construction of a resource - this time for foreign-language learning.

When one of the present authors (Bissell) gave his first paper in French a few years ago, he realised while preparing the text that he was unsure about certain technical terms or expressions. Available dictionaries, printed or online, were not very helpful or sufficiently up to date. However, by searching the Web for the proposed French terms he could find out whether they appeared in French web documents, and how often.

For example, should the technical term 'time domain' be translated into French as 'domaine de temps' or 'domaine temporel'? Each seemed plausible. Searching for each term via Google gave the statistics shown in Table 1 (at the time of writing), which suggested that 'domaine de temps' was the preferred alternative.

Now, this technique cannot indicate correctness or otherwise with certainty, although it can provide strong evidence in favour of one of the alternatives. Care is always needed concerning quality and authority - and there are plenty of web pages with poor grammar, spelling and vocabulary, or written by non-native speakers. In the case of French, too, there may be significant differences if the site originates in France, Canada, Belgium, Switzerland or francophone countries of Africa and Asia - even when produced by a competent native speaker.

Translation software can also be usefully used in a way not intended by its designers. Such tools are often either claimed to be far superior than they really are, or dismissed out of hand as completely inadequate. The truth is somewhere between. Figure 5 shows the apparently straightforward example of using translation software to translate a Russian sentence into English.

What it does not show, however, is that this is the final result of an interactive session in which the author ran some of a draft Russian text written for an evening class through a translation page back into English (back-translation). The stages not shown enabled him to correct some spellings and erroneous word endings. Again, the result cannot guarantee correctness, but it can indicate certain errors. So he was pleased when the final version returned almost exactly what he was trying to translate ("The English don't like being interviewed by foreign journalists"). ${ }^{3}$ Ironically, the better such translation software becomes in coping with spelling and grammatical errors, the less useful this approach will be.

\section{Looking ahead}

The case studies above show social construction of technology in an educational context, through the adaptation of existing, non-educational tools for an educational purpose. Our emphasis on 'use' (as opposed to creation) makes it inappropriate for

Table 1. Online frequencies for alternative French translations of 'time domain'.

\begin{tabular}{lcc}
\hline Translation & Pages from .fr sites & Total pages in French \\
\hline domaine temporel & 34,600 & 63,600 \\
domaine de temps & $30,600,000$ & $30,700,000$ \\
\hline
\end{tabular}




\section{Online - ПЕРЕВОДЧИК}

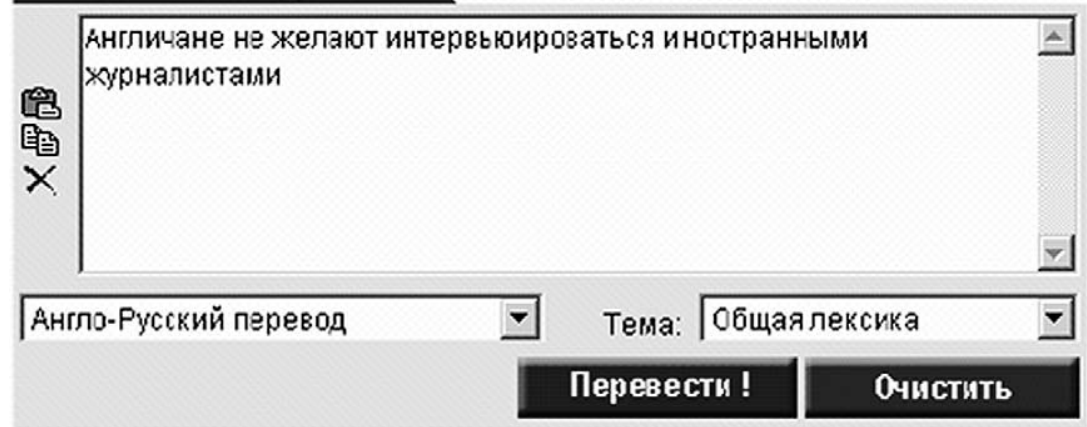

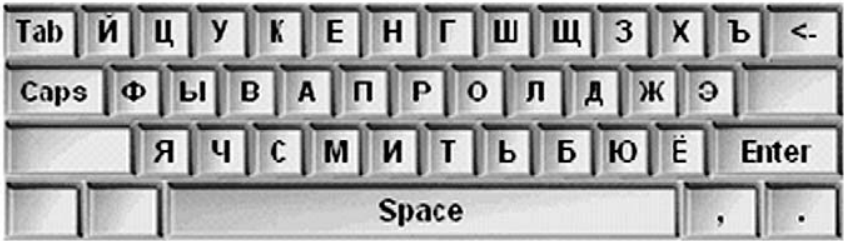

Хочешь переводить больше? Кипи программу-переводчик!

\section{Результат ПЕРЕВОДА}

Englishmen do not wish to be interviewed by fore ign journalists

\section{Pacпенатать \\ Oтправить e-mail \\ Лanee $\gg>$}

Figure 5. Screenshot of translation software.

us to offer general principles on the social construction of educational resources; the adaptation of tools for educational needs is a 'local' matter, to be undertaken where and when required, by those concerned.

Instead we offer a few final thoughts prompted by an area of technology that, at the time of writing, seems to offer novel educational possibilities: online social networks such as Facebook and Twitter. On the whole these resources have not been designed for educational use, and in the spirit of this article we believe that there are interesting possibilities for their use educationally - as others have suggested (for example, Madge et al. 2009; Ebner et al. 2010; Siemens and Weller 2011). However, we suggest that such uses should have an authentic aspect, which is not necessarily the same as using these resources in the way intended by their designers. Simply using these tools in the normal way would not in itself count as educational activity, nor as social construction. What is required is a learning activity within an authentic context. In the case of the audio and graphics editing packages discussed earlier, the educational function arose through a constructivist use of the tools for investigation of sound or image processing. An educationally productive use of new online communication tools might have a similar investigative quality - 
for example, through the investigation of network patterns in social networks. There is already a growing body of research in this area that exploits the statistically large datasets that social networks make available to investigators. (See for example Onnela and Reed-Tsochas 2010, who used Facebook to look at the role of social influence on the take-up and popularity of cultural products such as books, films and 'apps'; and Huberman and Szabo 2010, who investigated the prediction of longterm popularity of online content from initial comments and recommendations in Digg and Youtube).

\section{Conclusion}

This paper has made a case for using some ideas from science and technology studies in educational theory. Specifically, it has been concerned with a particular form of social shaping of technology known as SCOT. One principle of SCOT is that the 'meaning' of technology is not fixed by the design of the technology but arises through interaction between technology and its users. SCOT is markedly different from technological determinism, which views technology as an autonomous agent of change. Technological determinism underlies much of the popular discussion and journalism relating to technology, and is associated with claims for the transforming power of technological innovations, including in the field of education.

The SCOT perspective, in contrast, when applied to education, encourages educators to think about how established, non-educational tools can be used educationally. The word 'established' is important here because it is associated with authenticity. The tools that practitioners actually use are likely to be technologically mature and readily available. How such tools may be used educationally depends on the ingenuity of educators, but, as in many educational contexts, investigative and experimental procedures are at a premium. The case studies in this paper are merely indicative of what can be done. The authors' intentions, however, are that the examples given should be seen as constructivist in the two domains that intersect in this paper - the educational domain, through the constructivist pedagogies employed, and the technological domain, through the social construction of educational technology.

\section{Acknowledgements}

The authors are grateful to Dr Karen Kear for comments on earlier drafts of this paper. An earlier version of this paper was presented at the Seventh International Conference on Networked Learning, Aalborg, Denmark, 3-4 May 2010.

\section{Notes}

1. Equal temperament is the tuning system used on virtually all modern instruments in which the pitch of the available notes is determined by the instrument's construction and initial tuning (e.g. keyboard instruments, fretted instruments and, to a degree, many wind instruments). Excluded from this category are the violin family, the voice, and the trombone, where pitches are largely determined by the player (although with the violin family the tuning of the open strings fixes some notes).

2. 'Pure' and 'impure' frequency ratios can be exemplified by the ratio of the frequency of the home note of a major scale (i.e. the scale doh, re, me, etc.) and the frequency of the fifth note of the scale. The pure ratio is $1.5: 1$, determined by the series of harmonics found in nature in vibrating strings. The impure ratio used on equally tempered instruments is $(\sqrt{2})^{7}: 1$. This ratio is within $0.12 \%$ of the pure ratio. Equal temperament 
results in the instrument sounding equally harmonious in all keys (i.e. in scales based on any note), although some purists would rather say equal temperament was equally inharmonious in all keys. With pure ratios, some keys are harmonious but others are severely out of tune.

3. Unfortunately, when the tutor read it, she uttered that phrase so hated by language learners: "I'm sorry, we just don't say that in Russian". Like the computer program behind the translation page, the author had mastered (some of) the rules - but was still a novice in the culture.

\section{References}

Abbey, B., ed. 2000. Instructional and cognitive aspects of web-based education. Hershey, PA: Idea Group Publishing.

Anon, n.d. One laptop per child website. http://one.laptop.org/about/education (accessed June 29, 2011).

Batchelor, S. 2005. Money talks: Sending money home outside the envelope. Developments, 31. http://www.mendeley.com/research/money-talks-sending-money-home-outside-envelope/ (accessed June 28, 2011).

Benson, H., and J. Kopp. 1991. Spreadsheet physics: Study units for university physics. New York: Wiley.

Berg, J.-K., and E. Selinger, eds. 2007. Philosophy of technology: 5 questions. New York: Automatic Press/VIP.

Bijker, W.E. 1995. Of bicycles, bakelites, and bulbs: Toward a theory of sociotechnical change. Cambridge, MA: MIT Press.

Bijker, W.E., T.P. Hughes, and T.J. Pinch, eds. 1987. The social construction of technological systems. Cambridge, MA: MIT Press.

Bijkjer, W.E., and J. Law, eds. 1992. Shaping technology/building society: Studies in sociotechnical change. Cambridge, MA: MIT Press.

Brown, J.S., A. Collins, and P. Duguid. 1989. Situated cognition and the culture of learning. Educational Researcher 18, no. 1: 32-42.

Creanor, L., K. Trinder, D. Gowan, and C. Howells. 2008. Life, learning and technology: Views from the learners. Learning and Teaching in Higher Education 2: 26-41.

Cuban, L. 1986. Teachers and machines: The classroom use of technology since 1920. New York: Teachers College.

Ebner, M., C. Lienhardt, R. Matthias, and I. Meyer. 2010. Microblogs in higher education A chance to facilitate informal and process-oriented learning? Computers and Education 55: 92-100.

Edgerton, D. 1998. De l'innovation aux usages. Dix thèses éclectiques sur l'historie des techniques. Annales histoire, sciences sociales 53, nos. 4-5: 815-35.

Edgerton, D. 1999. From innovation to use: Ten (eclectic) theses on the history of technology. History and Technology 16: 1-26.

Edgerton, D. 2006. The shock of the old: Technology and global history since 1900. London: Profile.

Healy, L., and R. Sutherland. 1992. Exploring mathematics with spreadsheets. Oxford: Blackwell Education.

Huberman, B., and G. Szabo. 2010. Predicting the popularity of online content. Communications of the ACM 53, no. 8: 80-8.

Kear, K. 2004. Peer learning using asynchronous discussion systems in distance education. Open Learning 19, no. 2: 151-64.

Kear, K. 2011. Online and social networking communities: A best practice guide for educators. New York: Routledge.

Kral, I.H. 1991. The Excel spreadsheet for engineers and scientists. Englewood Cliffs, NJ: Prentice Hall.

Kline, R., and T. Pinch. 1996. Users as agents of technological change: The social construction of the automobile in the rural United States. Technology and Culture 37, no. 4: 763-95. (Extract from pages 765-7 repr. MacKenzie and Wajcman 1999, 113-15.)

Lave, J. 1998. Cognition in practice. Cambridge: Cambridge University Press. 
Madge, C., J. Meek, J. Wellens, and T. Hooley. 2009. Facebook, social integration and informal learning at university: It is more for socialising and talking to friends about work than for actually doing work. Learning, Media and Technology 34, no. 2: 141-55.

Mayes, T., and S. de Freitas. 2007. Learning and e-learning. In Rethinking pedagogy for a digital age, ed. H. Beetham and R. Sharpe, 13-25. London: Routledge.

MacKenzie, D., and J. Wajcman, eds. 1999. Social shaping of technology. 2nd ed. Milton Keynes: Open University Press.

Onnela, J.-P., and F. Reed-Tsochas. 2010. Spontaneous emergence of social influence in online systems. Proceedings of the National Academy of Sciences of the USA 107, no. 43: $18375-80$.

Pettit, J., and A. Kukulska-Hulme. 2007. Going with the grain: Mobile devices in practice. Australasian Journal of Educational Technology 23, no. 1: 17-33. http://www.ascilite. org.au/ajet/ajet23/pettit.html (accessed June 25, 2011).

Pinch, T., and W. Bijker. 1986. Science, relativism and the new sociology of technology: Reply to Russell. Social Studies of Science 16: 347-60.

Schroeder, R. 2007. Rethinking science, technology, and social change. Stanford, CA: Stanford University Press.

Siemens, G., and M. Weller. 2011. Higher education and the promises and perils of social network. Revista de universidad y sociedad del conocimiento 8, no. 1: 164-70, (RUSC).

Smith, H.L., S. Higgins, K. Wall, and J. Miller. 2005. Interactive whiteboards: Boon or bandwagon? A critical review of the literature. Journal of Computer Assisted Learning 21, no. 2: 91-101.

Smith, M.R., and L. Marx. 1995. Does technology drive history? Cambridge, MA: MIT Press.

Stanton, B.J., M.J. Drozdowski, and T.S. Duncan. 1993. Using spreadsheets in student exercises for signal and linear system analysis. IEEE Transactions on Education 36, no. 1: $62-8$.

Williams, R., and D. Edge. 1996. The social shaping of technology. Research Policy 25: 856-99. 